\title{
Robotics as an instrument for social mediation
}

\author{
Mario Toboso, Ricardo Morte, Aníbal Monasterio, Txetxu Ausín, Manuel Aparicio and Daniel López
}

\begin{abstract}
The relationship of a community with a robotic device happens by means of a social discourse comprised of social values, practices and representations of this device. But the robot that connects with the user community also brings with it values, practices and representations coming from the communities responsible for its idea, design, development and manufacturing, marketing, commercialization and distribution. This artefactual discourse, brought to life in the device, is present in the environments where it is used and might come to modify the discourse in the community. As devices that mediate actions, robots not only transforms the practices carried out in an environment, but also its characteristic values.
\end{abstract}

\section{INTRODUCTION}

$\mathrm{D}$ ifferent environments for activities and social participation, such as the urban environment, domestic environment, educational environment, work environment, environments for public, political, social and economic participation, environments for information, communication, science, culture, leisure or health, can be considered "functionings environments," in the sense of the capability approach from Amartya Sen and Martha Nussbaum. This idea deals with spaces (real or virtual) where we carry out actions and practices we consider to be important and valuable for our wellbeing and quality of life [1]. In this approach, wellbeing consists of evaluating life conditions defined by functionings. These represent what a person achieves or becomes in the development of their life, which can be considered a set of interrelated functionings [2], [3].

It is characteristic of functionings environments to contain a diversity of possible functionings in them, an aspect that relates to one of the dimensions in the "functional diversity" concept [4], which can be integrated quite naturally into the capability approach.

The introduction of technological elements and, in particular, robotic elements, into functionings environments condition the way in which the actions are carried out and, consequently, can modify evaluation of the functionings that

This paper benefits from Grant Agreements 780073-INBOTS and 779982-EXTEND.

M. Toboso is a Tenured Scientist at the Department of Science, Technology and Society in the Institute of Philosophy of the Spanish National Research Council, Madrid, Spain (mario.toboso@csic.es).

$\mathrm{R}$. Morte is a Ph.D. Student at the University of Granada, Granada, Spain (ricardo63@autistici.org).

A. Monasterio is a Basque Government Posdoctoral Researcher, Bilbao, Spain (anibal.monasterio@ehu.eus).

T. Ausín is a Tenured Scientist at the Department of Theoretical and Practical Philosophy in the Institute of Philosophy of the Spanish National Research Council, Madrid, Spain (txetxu.ausin@cchs.csic.es).

M. Aparicio is an Associate Professor at the University of Murcia, Murcia, Spain (manuel.aparicio@um.es).

D. López is a Predoctoral Researcher at the Department of Theoretical and Practical Philosophy in the Institute of Philosophy of the Spanish National Research Council, Madrid, Spain (daniel.lopez@csic.es).

They constitute the IFS-CSIC Research Group in INBOTS and EXTEND projects. are mediated by such elements. We can verify this statement by looking at the case of smartphones, a mediation technology present today in practically every environment: as almost everything we do is now done with this device, it appears that its use even defines what is valuable to do; it is as if the actions we do by means of using this device have greater value than those that do not need it, The practice of use of the device seems to define the value of what we do with it.

The technologies for mediating functionings introduce, then, their own artefactual discourse into the functionings environments. Further on we will delve into the normative dimension linked with the practices of technological use. This normative dimension accounts for the discursive nature of this use and its axiological dimension.

\section{MATERIAL AND METHODS}

These are the conceptual materials that make up the basis of our reflections. On the one hand, the capabilities approach of Sen and Nussbaum, in terms of a widely-accepted and influential ethical-political paradigm. On the other, we adopt a "discursive" approach on the relationship between users and technologies, where we take into consideration the respective sets of values, representations and social practices that shape each discourse, that of the users and that of the artefactual discourse brought to life by technological devices. An important aspect in this communication concerns the relationship between values such as security, intimacy or privacy, which are present in both discourses.

The methods used are of a philosophical nature and involve a review of the pertinent literature, an analytical reading of the selected bibliography and analysis of ideas related to technological mediation and, in particular, with mediation by robots, such as: functionings environments, adoption, technological dependency and appropriation, digital and robotic divides, barriers, equal opportunity, wellbeing, quality of life, security, intimacy and privacy in the use of technological devices. All of this is situated within the central question of robotics as an instrument for social mediation.

\section{RESUlts}

If a given functioning can be done by means of mediation from a robot and also without its mediation, we have two functionings tied to the same action. The introduction of robotic devices into functionings environments can give rise, then, to new functionings, and this would suggest enrichment of these environments. Presently this can clearly be seen, for example, in cases where certain technologies are introduced as mediators in administrative procedures and paperwork that traditionally were done only in person. 
Nevertheless, usually the new mediated functioning does not coexist with the traditional one, but rather, based on utilitarian and economistic arguments, causes it to disappear. As a result, functionings environments become robotized but not enriched by an increase in possible functionings, which could serve the diversity of functional needs of the user communities in a more precise way.

Taking into consideration human diversity, of individual characteristics as well as contextual circumstances, constitutes a very important aspect in Amartya Sen's capability approach [3]. The relationship has already been noted between the concept of functional diversity and the importance of considering human diversity in Sen's approach, making the case that this consideration should also be broadened to include the particular characteristics of realising the different functionings. In an evaluation of wellbeing and quality of life, the "capability set" (which can be interpreted as the set of functionings that are of value to people, carried out in their relevant environments) should include all the variety of possibilities in the performance of valued functionings, in line with the fact that different people have different ways of achieving identical functionings. Thus, for each particular functioning it should be taken into account the different possible ways of carrying it out and not be limited to the majority, standard and most common ways.

The assumed margins of functional normality are very narrow, and to be outside of them implies accepting the diversity of functionings that have been altered by circumstances. An inclusive society that aspires to equal opportunities should promote and keep these other possible functionings active so that a larger number of people can have access to them if they need them. This is one of the reasons why we consider it important and necessary to value functional diversity socially, given that this expands the space of possibilities for functioning to other less common ways that, nevertheless, could be taken advantage of by everyone [4].

The wider the set of functionings available in a society the more inclusive it will be, and it will offer greater life possibilities to people. A set like this will also offer greater freedom of choice and will favour equal opportunities.

If in a given environment the situation arises in which mediation from a device is obligatorily needed to perform a certain functioning, the limitations of this device will define the limitations of this action. In the most extreme case, but at the same time the most evident, if the device is not available, performance of the functioning will be nullified, which will negatively affect the scope of wellbeing associated with its achievement.

When "doing something" implies being able "to do it only by means of certain devices," barriers to access or use will create discrimination and inequality in the user communities, as a consequence of their artefactual dependency on such devices. Artefactual dependency is one of the undesirable effects of its adoption. In the case of robotic devices, the barriers will produce a "robotics divide" analogous to that already known as the "digital divide." These "divides" reflect inequalities of access and use, whose combination produce an inequality of greater importance: inequality of opportunities for the affected people or communities. Demanding genuine equal opportunities brings up important questions having to do with ethics, politics and social justice, and related to which value frameworks should be considered the most relevant when considering what is needed for equality.

\section{DiscusSION}

Let's consider how a particular device becomes an innovation. Initially, we can call what is introduced into a particular environment of functionings "proposed innovation," and this proposal does not become an "effective innovation" (or simply an innovation) until it is adopted socially by the community or group it is aimed at [5]. The characteristics of this adoption process are quite varied, given that how a community or group approaches a proposed innovation happens by means of sets of social representations, practices and values regarding the innovation.

Functionings environments are discursive spaces (of practices and of representations) where the values that characterise them and, in a certain sense, define them, "live." The relationship between sets of practices and representations in a given environment are mediated by the environment's own characteristic values.

Let's take a hospital as an example of a functionings environment. We immediately notice that it is a space riddled with its own characteristic values: implicit and explicit functioning codes, protocols and regulations that must be fulfilled; these guide practices and representations that define the characteristics of such an environment, the hospital, as a discursive space.

Now, let's look at the case of a community that begins a relationship with a certain technology by means of sets of social values, representations and practices of the community in regard to it. This way of understanding the relationship allows us to talk about the community's discourse about this technology. But there is an analogous discourse, linked to the technology in question, which also brings with it values, practices and representations coming from the communities responsible for its idea, design, development, manufacturing, marketing and commercialisation. This artefactual discourse, materialised in the technology, is introduced into the functionings environments where it is used and can come to modify the community's discourse.

The aspects that a community of users can evaluate in their relationship with any type of device are very numerous. Among them we highlight the following values [6], distributed in the instrumental dimension in connection with access and use, and in the functional dimension linked to security and privacy: availability, affordability, necessity, 
appearance, simplicity, ergonomics, accessibility, usability, versatility, efficiency, quality, reliability, security, intimacy and privacy.

But it is also necessary to evaluate devices in an ethical dimension. To do this, it is essential to define what criteria, which values should be taken into account in the evaluation. Accordingly, Romero [7] considers the following four principles in order to create a more complete evaluation process for technological devices:

1. Sustainability: requires verifying and analysing the impact of technologies on the contamination of land, the atmosphere, or on the system for recycling materials.

2. Precaution: parallel to the principle of nonmaleficence (one of the traditional principles in Bioethics), this criteria supports adopting cybersecurity and protective measures to confront the suspicions related to future risks associated with the implementation and use of certain technologies. This principle should involve carrying out evaluations on impacts prior to their implementation.

3. Privacy: the user should know or be informed about privacy procedures online, for their security and anonymity, as well as about the privacy systems in the hardware and software. At this point it should be remembered that, with regard to privacy, in addition to a personal dimension, this is also present socially. One of the key functions of privacy is to control the perverse and abusive consequences deriving from the asymmetrical power relationships between individuals and organizations.

4. Democracy: along with the principle of autonomy, the defence of digital rights should be promoted, in institutional organisms, as Human Rights, just the same as cybersecurity in domestic, professional, state and crucial infrastructures (such as hospitals, nuclear power plants, airports, water supplies, etc.). The definition of this principle poses some problems and could be substituted by the possibility of citizens being able to intervene in the procedures used for handling data in these institutions and infrastructures.

Let's now consider how the practice of using a technology is connected to the values that motivate said practice and, at the same time, how it can come to define these values. In the first case, we assume the motivational priority of the users' discourse over the artefactual discourse. That is, certain values forming part of the users' discourse motivate and guide them towards the practice of using the technology in question. In the second case, we have the priority of the practice of use over the value, which reflects the priority of the artefactual discourse over the community's discourse, as if through this practice of use the values that motivate the practice are constructed and encouraged, in a type of circular feedback.

We could ask ourselves if the "value" appearing in both cases is the same. That is, does the value from the community (which motivates the practice of use of the technology) coincide with the artefactual value (that is encouraged by said practice)? Usually these values are different, and the difference between both is precisely what accounts for the difference between the community's discourse and the technology's artefactual discourse. In the case in which both values coincide it could be said, in respect to this value, that both discourses are concurrent and that the technology in question "satisfies," optimally, the motivational value of the community. Easily understandable and desirable examples of this satisfaction are those that refer to values, for example, such as availability, price, accessibility, quality or security in the use of the technology in question.

The satisfaction of values, such as those previously referred to (instrumental, functional, ethical and others), which can also be interpreted as the concurrence in them of the community's discourse and the artefactual discourse, is the basic condition for "social appropriation" of the devices by the community, which we should differentiate from the simple concept of "adopting" them. Adoption happens through the practice of use, as if it was simply guided by artefactual values, while appropriation happens by means of the co-constructive combination of practices and values, requiring as such satisfaction of these values in practices, as values from the community, and also involves social representations that are favourable towards the device in question [4].

One of the most important dimensions of social appropriation is the axiological dimension, which relates to the values that guide the practices and representations that different communities have in the functionings environments coming from the implicated innovations.

Within a research on inclusive robotics for a better society, we should ask ourselves which aspects of current society are the ones seeked to improve with the introduction of these robotics. We could also ask which human functionings environments aspire to be better, and to what extent, by means of said introduction. Among such environments of social practices, we will have to consider the educational environment, the work environment, the care and assistance environment, the home or environments for social participation.

More than one hundred years ago, Schumpeter spoke about processes for innovation as being "creative destruction" [8]. Recently, Javier Echeverría has been reflecting on the good and bad of innovation, assuming that all innovation has its beneficiaries but also those who are harmed [5]. The question that concerns us is how to distribute the benefits and the damages. It would be desirable for this to be done in a just and equitable way toward the conditions of functionings environments, on which the wellbeing and quality of life of people may, critically, depend.

Following these considerations and applying them to the case of interactive robotics, using a qualifier for such "interaction" could be considered as a start to speaking in a different way about constructive interaction or destructive interaction. In such a case, the conditions of possibility and characteristics of constructive interaction could be evaluated 
based on encouraging and promoting the values specific to the environment in question, these values being desirable and widely-shared by the different actors that form part of it. Constructive interaction would be whatever contributes to sustaining the previous structure and conditions that make up the environment, even being able to improve some aspects of them. In a work environment, for example, such shared values can be identified. Other values, conversely, may not be so, but rather specifically and distinctly characterise the particular discourse and practices of certain actors, such as when the introduction of technical elements, innovations, machinery, robots, etc., into the environment are motivated by private values or interests aimed exclusively at economic performance [9].

\section{CONCLUSIONS}

The introduction of devices (technological, robotics, etc.) in functionings environments conditions and modifies the way in which these environments are formed. Their mediation will determine the character of the mediated functionings and the way to carry them out. As such, it involves modification of the original functionings, which will transform into the "mediated" ones. In general, this mediation implies adaptation of the users' discourse to the artefactual discourse materialized in the devices [10], which produces a transformation not only in the landscape of practices in the environment, but also in the panorama of its values.

The introduction of robotic mediation elements can notably affect the structure of the functionings environments, just like when, in the same way, the biological balance of an ecosystem is affected if an invasive or predatory species is introduced. Similarly, the balance in the space from the functionings that certain actors do within this environment can be critically affected.

In the case of the work environment, the functionings affected refer directly to the daily chores and circumstances that constitute the work itself of the workers in their posts [11]. In the same way, profoundly transformative effects can be predicted in the educational environment, with the promotion of education mediated by assistants, now not technological but rather robotic, and with the consequent introduction of the figure of the robotic professor. The same influence is currently predicted in care-giving environments, where the supposed advantages of affective robots, robotic assistants and care-giving robots are already being advertised. This is being done without taking into account that care-giving relationships imply elements that are essentially human, intrinsically intersubjective, and to care for a person with Alzheimer's, to name one case, the best "technology" is another human being [12].

In relation to this, one of the relevant aspects we propose is to study the effect of interactive robotic devices on the wellbeing and quality of life of people and communities by means of the capabilities approach and functionings of Amartya Sen and Martha Nussbaum. The main advantage of using this approach for analysing the effect of robotic innovations on functionings environments is that it introduces important ethical and social considerations about questions that, at first glance, could appear to only be technical or instrumental.

\section{REFERENCES}

[1] M. C. Nussbaum \& A. Sen (Eds.), The Quality of Life, New York: Oxford University Press, 1993.

[2] A. Sen, "The Standard of Living", in G. Hawthorn (Ed.), The Standard of Living. Cambridge: Cambridge University Press, 1987.

[3] A. Sen, Inequality Reexamined, Harvard: Harvard University Press, 1998.

[4] M. Toboso, "Rethinking disability in Amartya Sen's approach: ICT and equality of opportunity", Ethics and Information Technology, 13(2), 2010, pp. 107-118.

[5] J. Echeverría, Innovation and Values: A European Perspective, Reno, NV, University of Nevada Reno, Center of Basque Studies, 2014.

[6] J. Echeverría, "Science, technology, and values: towards an axiological analysis of techno-scientific activity", Technology in Society, 25, 2003, pp. 205-215.

[7] J. Romero, "CiberÉtica como ética aplicada: una introducción", Dilemata. Revista Internacional de Éticas Aplicadas, 24, 2017, pp. 45-63.

[8] J. A. Schumpeter, Theorie der wissenschaftlichen Entwicklung, Berlin, Duncker \& Humblot, 1912: english translation, The Theory of Economic Development, Boston, Harvard University Press, 1934.

[9] E. Brynjolsson and A. Mcfee, Race Against the Machine: How the Digital Revolution is Accelerating Innovation, Driving Productivity, and Irreversibly Transforming Employment and the Economy, Lexington, Massachusetts, Digital Frontier Press, 2011.

[10] L. Winner, "Is there a right to shape technology?", Argumentos de Razón Técnica, $\mathrm{n}^{\circ}$ 10, 2007, pp. 305-328.

[11] M. Goos, "The impact of technological progress on labour markets: policy challenges", Oxford Review of Economic Policy, Volume 34, Issue 3, 2018, pp. 362-375.

[12] R. de Asís Roig, "Ethics and Robotics. A First Approach", The Age of Human Rights Journal, № 2, 2014, pp. 1-24. 